\title{
Caesarean Section Audit: The Use of the Robson's Criteria in a Teaching Hospital with Limited Advanced Fetal Surveillance
}

\author{
Babatunde Ajayi Olofinbiyi ${ }^{*}{ }^{\text {, }}$, Jacob Olumuyiwa Awoleke ${ }^{1}$, Oluwole Dominic Olaogun ${ }^{1}$, Adeyemi Sunday \\ Adefisan ${ }^{2}$, Oluwafunke Rebecca Olofinbiyi ${ }^{3}$, Adeola Olabisi Awoleke ${ }^{4}$, Temitope Omoladun Okunola ${ }^{1}$ \\ ${ }^{1}$ Department of Obstetrics and Gynaecology, College of Medicine, Ekiti State University, Ado-Ekiti, Nigeria. \\ ${ }^{2}$ Department of Obstetrics and Gynaecology, Ekiti State University Teaching Hospital, Ado-Ekiti, Nigeria. \\ ${ }^{3}$ Department of Nursing Science, Babcock University, Ilishan-Remo, Nigeria. \\ ${ }^{4}$ School of Nursing, Ekiti State University Teaching Hospital, Ado-Ekiti, Nigeria.
}

*Corresponding Author: Babatunde Ajayi OLOFINBIYI; babatunde.olofinbiyi@eksu.edu.ng

Received 05 June 2020;

Accepted 27 June 2020;

Published 03 July 2020

\begin{abstract}
Background: Rising caesarean section rates have become a global health concern. The need for a contemporary objective tool for comparison of rates, optimizing and standardizing the use of caesarean section has been met by the Robson's Ten-Group classification. However, there are no available studies auditing caesarean section rates in southern Nigeria using these criteria. Methods: All mothers delivered by caesarean section over a 12-month period at Ekiti State University Teaching Hospital, Ado - Ekiti, were prospectively captured and classified according to Robson's 10-group classification with a view to detecting which clinically relevant groups contributed most to the caesarean section rate. Data collected were analyzed using Statistical Package for Social Sciences (SPSS) 20. Results: The total deliveries recorded over the study period was 2,139, out of which 760 underwent caesarean section, thus giving a Caesarean Section Rate of 35.5\%. Group 1 had the highest contribution to Caesarean section rate, followed by Group 5. There was a statistically significant relationship between booking status of the patients and the various groups in the Robson's classes $(\mathrm{p}<0.001)$. Conclusion: There should be continuous training and drills on active management of labour, supportive companionship in labour, and improved fetal surveillance techniques to reduce the rates of primary caesarean section. Developing locally-adapted eligibility criteria to increase successful trials of labour after caesarean section, revisiting external cephalic version, and addressing potentially modifiable risks for preterm birth are advocated.
\end{abstract}

Keywords: Caesarean section rate, audit, Robson's classification.

\section{Introduction}

Caesarean delivery, surgical incisions on the anterior abdominal wall and uterus to deliver a viable fetus, is a commonly performed surgical operation and one of the oldest major obstetric procedures [1]. It is an important arm of essential obstetric care that has remained a major area of interest and focus in contemporary obstetric practice. The roles of caesarean section (CS) in the prevention of maternal and perinatal morbidity and mortality cannot be overemphasized at not more than a threshold rate of $15 \%$, as recommended by the World Health Organization (WHO) ${ }^{[2,3]}$. However, caesarean section rate (CSR) of more than $15 \%$ has not been shown to contribute appreciably to further reduction in maternal and perinatal morbidity and mortality ${ }^{[4,5]}$. The last five decades have witnessed undue rise in CSR worldwide, with figures as high as $58.6 \%-70.6 \%$ recorded in some parts of the world ${ }^{[6]}$. It is even interesting to find out that the undue rise in CSR is also witnessed by developing countries like Nigeria where aversion for CS is still relatively high ${ }^{[7,8,9]}$. The rapidly increasing CSR has been strongly linked with patients' desire for small family size, fear of litigation for any error during the delivery process on the part of healthcare providers, high threshold for vaginal birth after CS, improper conduct of induction of labour, advent of continuous electronic fetal monitoring and loss of interest/skills in assisted vaginal delivery and related maneuvers, convenience of physician, maternal request and financial incentives ${ }^{[7,10]}$. This challenge of undue increase in caesarean section rate has informed the need for standardization and reliable comparison of CSR which Robson's Ten-Group classification has emerged to address ${ }^{[11,12]}$. This classification, which is essentially an objective contemporary tool for optimizing and standardizing the use of caesarean delivery, was adopted by WHO and International Federation of Obstetrics and Gynaecology (FIGO) in 2014 and 2016 respectively ${ }^{[11,12]}$. 
Therefore, the objective of this study is to audit the CSR in our institution using the Robson's 10 group classification that makes use of five (5) characteristics of pregnancy: single or multiple pregnancy; nulliparous, multiparous, or multiparous with previous CS; cephalic, breech presentation or other presentation; spontaneous or induced labour; and term or preterm births. To the best of our knowledge, none of the available studies on CS has utilized the Robson's classification in auditing CSR in the environment of study. The findings of this study would not only add to the existing body of knowledge on caesarean section, but also give direction to the interventions targeted at reducing the rising caesarean section rate.

\section{Materials and Methods}

This was an observational and prospective study carried out at the Department of Obstetrics and Gynaecology of Ekiti State University Teaching Hospital (EKSUTH), Ado-Ekiti, southwest Nigeria from 1st of January, 2015 to 31st December, 2015. The tertiary facility is the Teaching Hospital for the College of Medicine, Ekiti State University, Ado-Ekiti, Nigeria, that turned out its first set of medical graduands in July, 2019. The teaching hospital serves as the main referral centre for private, primary and secondary health institutions in the state and parts of the neighbouring states like Osun, Kogi, Kwara and Ondo. The hospital runs weekly antenatal clinics and 24-hour emergency obstetric and gynaecological services.

Feto-maternal socio-demographic and clinical characteristics were extracted into a large obstetric database using a comprehensive proforma comprising about ninety items and covering over 180 variables. These variables included sociodemographic data, previous obstetric and gynaecological information, index pregnancy's antepartum, intrapartum and postpartum events with observed complications and perinatal outcomes. The data were obtained from parturients' case folders and complemented with relevant additional pieces of information from parturients themselves and nurses' record sheets to ensure completeness. Patients delivered by CS during the study period were recorded and classified to Robson's 10 group classification system as shown in Table 1. The parameters considered were according to the classification system: parity (with/without previous CS); gestational age ( $\geq 37 / \leq 36$ weeks); fetal presentation (cephalic/breech/abnormal lie); number of fetuses (singleton/ multiple); and onset of labour (spontaneous/ induced/ pre-labour $\mathrm{CS})$. The patients were regarded as unbooked if they did not receive antenatal care at all, or had antenatal supervision by a traditional birth attendant, at a peripheral or private hospital, and were only referred to EKSUTH when a complication developed during pregnancy or labour.

The information was obtained in real time by a trained research assistant and community health officer employed full time for obstetric database collection. Approval for the study was obtained from the hospital's Ethics and Research Committee.

Data collected were analyzed using Statistical Package for Social Sciences (SPSS) version 20. Descriptive statistics was used to analyze the data, with results expressed as numbers and percentages. Univariate association between the booking status of the patients and the Robson's classes was explored using the Pearson's chi-square test, with significance levels set as $\mathrm{p}<0.05$.

\section{Results}

Table 2 shows the distribution of deliveries according to Robson's Classification. The total number of deliveries recorded during the study period was 2,139 , out of which 760 were by CS, thus giving a caesarean section rate of $35.5 \%$.

Group 1 (nulliparous, singleton, cephalic, $\geq 37$ weeks, spontaneous, labour) had the highest contribution to CSR (8.2\%), followed by Group 5 (multiparous with prior CS, singleton, cephalic, term) that contributed 6.6\%, and Group 10 (Singleton, cephalic, preterm, previous CS) with $5.9 \%$. Although all parturients in Group 9 had CS (100\% CSR for the group), it had the least contribution, $10 / 2139(0.5 \%)$, to the overall CSR.

Table 3 shows univariate association between Robson's groups and booking status. While $62.4 \%$ of the patients that had CS were booked, $37.6 \%$ were unbooked. There was a statistically significant relationship between booking status of the patients and CSR ( $\mathrm{p}<0.001)$. Furthermore, while Groups 2 (7.8\% versus $1.7 \%), 4$ (3\% versus $0.3 \%), 5(24.3 \%$ versus $9.4 \%)$, and $9(1.5 \%$ versus $1 \%$ ) had a greater proportion of the CS performed on booked patients, all the remaining groups had a preponderance of the operation performed on patients who were unbooked.

Table 1: Criteria for Robson's 10-group classification

\begin{tabular}{|c|l|}
\hline Group & Clinical Parameters \\
\hline 1 & Nulliparous, singleton, cephalic, $\geq 37$ weeks, spontaneous labour \\
\hline 2 & Nulliparous, singleton, cephalic, $\geq 37$ weeks, induced labour or caesarean section before labour \\
\hline 3 & Multiparous without previous caesarean section, singleton, cephalic, $\geq 37$ weeks, spontaneous labour \\
\hline 4 & Multiparous without previous caesarean section, singleton, cephalic, $\geq 37$ weeks, induced labour or caesarean section before labour \\
\hline 5 & Multiparous with prior caesarean section, singleton, cephalic, $\geq 37$ weeks \\
\hline 6 & All nulliparous breeches \\
\hline 7 & All multiparous breeches (including previous caesarean section) \\
\hline 8 & All multiple pregnancies (including previous caesarean section) \\
\hline 9 & All pregnancies with transverse or oblique lie (including previous caesarean section) \\
\hline 10 & Singleton, cephalic, $\leq 36$ weeks (including previous caesarean section) \\
\hline
\end{tabular}

Table 2: Distribution of deliveries according to Robson's classification

\begin{tabular}{|l|l|l|l|l|l|}
\hline Group & $\begin{array}{l}\text { Deliveries per } \\
\text { group }\end{array}$ & CS per group & $\begin{array}{l}\text { CS Rate (\%) per } \\
\text { group }\end{array}$ & $\begin{array}{l}\text { Contribution of group to } \\
\text { total deliveries (\%) }\end{array}$ & $\begin{array}{l}\text { Contribution of group to overall } \\
\text { CS rate (\%) }\end{array}$ \\
\hline 1 & 569 & 176 & 30.9 & $26.6(569 / 2139)$ & 8.2 \\
\hline 2 & 105 & 42 & 40 & $4.9(105 / 2139)$ & 2 \\
\hline 3 & 700 & 121 & 17.3 & $32.7(700 / 2139)$ & 5.7 \\
\hline 4 & 68 & 15 & 22.1 & $3.2(68 / 2139)$ & 0.7 \\
\hline 5 & 176 & 142 & 80.7 & $8.2(176 / 2139)$ & 6.6 \\
\hline
\end{tabular}




\begin{tabular}{|l|l|l|l|l|l|}
\hline 6 & 51 & 41 & 80.4 & $2.4(51 / 2139)$ & 1.9 \\
\hline 7 & 79 & 59 & 74.7 & $3.7(79 / 2139)$ & 2.8 \\
\hline 8 & 37 & 28 & 75.7 & $1.7(37 / 2139)$ & 1.3 \\
\hline 9 & 10 & 10 & 100 & $0.5(10 / 2139)$ & 0.5 \\
\hline 10 & 344 & 126 & 36.6 & $16.1(344 / 2139)$ & 5.9 \\
\hline TOTAL & 2,139 & 760 & & 100 & 35.5 \\
\hline
\end{tabular}

Table 3: Univariate association between Robson's groups and booking status

\begin{tabular}{|c|c|c|c|c|}
\hline \multirow[t]{2}{*}{ Groups } & \multicolumn{2}{|l|}{ Booking status } & \multirow[t]{2}{*}{$x^{2}$} & \multirow[t]{2}{*}{ p value } \\
\hline & Unbooked, n (\%) & Booked, n (\%) & & \\
\hline 1 & $85(29.7)$ & $91(19.2)$ & \multirow{11}{*}{56.62} & \multirow{11}{*}{$<0.0001 *$} \\
\hline 2 & $5(1.7)$ & $37(7.8)$ & & \\
\hline 3 & $53(18.5)$ & $68(14.3)$ & & \\
\hline 4 & $1(0.3)$ & $14(3)$ & & \\
\hline 5 & $27(9.4)$ & $115(24.3)$ & & \\
\hline 6 & $21(7.3)$ & $20(4.2)$ & & \\
\hline 7 & $27(9.4)$ & $32(6.8)$ & & \\
\hline 8 & $14(4.9)$ & $14(3)$ & & \\
\hline 9 & $3(1)$ & $7(1.5)$ & & \\
\hline 10 & $50(17.5)$ & $76(16)$ & & \\
\hline TOTAL & 286 & 474 & & \\
\hline
\end{tabular}

\section{Discussion}

Audit of caesarean delivery using Robson's criteria was done for the first time at the centre of study. To ensure robustness, each group was sub-stratified to determine the contribution from booked and unbooked parturients. The CSR was $35.5 \%$. This was much higher than $18.8 \%$ recorded in Southeast Nigeria ${ }^{[8]}$, and $11.3 \%$ documented by Daniel and Singh in Northwest Nigeria ${ }^{[7]}$, but similar to the rate obtained from another tertiary centre in Southwest Nigeria ${ }^{[9]}$. The three centres are in different geopolitical zones of Nigeria. These wide differences in CSR among the three geopolitical zones could be a reflection of the different levels of literacy, cultural norms and variations in health-seeking behaviour of the populace ${ }^{[13,14]}$. Our centre's CSR of $35.5 \%$ is much higher than the recommended rate of $15 \%$ by the WHO ${ }^{[2,3]}$, and also higher than the average rate $(31.1 \%)$ quoted in the USA ${ }^{[15,16]}$, and $27.9 \%$ in Brazil ${ }^{[17]}$.

In this study, Robson's Group 1 (nulliparous, singleton, cephalic, term, with spontaneous labour) had the highest contribution to the CSR. Other studies have observed that Group 5 (multiparous, previous caesarean section, single, cephalic, term) ${ }^{[18]}$, and Group 2 (nulliparous, singleton, cephalic, term, induced labour or Caesarean section before labour) ${ }^{[19]}$ contributed most to the CSR in their institutions. This observation from the index study could be the outcome of poorly managed labour in maternity facilities within the community. This is evidenced by the fact that a significant proportion (29.7\%) of these parturients had been managed outside of the Teaching Hospital. These unbooked patients are usually referred from mission homes, traditional birth attendants, and private health facilities with obstetric complications. When the clients are later referred to EKSUTH, the likelihood of an emergency caesarean delivery is higher in order to minimize adverse perinatal outcomes. This highlights the need for universal access to skilled attendants during delivery in our locality. However, since this group also included a large percentage of booked clients $(19.2 \%)$ managed completely at EKSUTH, the availability of more advanced intrapartum fetal surveillance equipment like cardiotocograph, intrauterine pressure monitors, and fetal scalp blood sampling techniques, will guide decision- making and reduce the use of caesarean section as a 'defensive' modality against medico-legal litigations. Studies have shown that women who had one-to-one companionship in labour were less likely to require analgesia, caesarean and operative vaginal deliveries, especially in localities without routine epidural analgesia in labour ${ }^{[20]}$. Integrating this into labour management in nulliparous women (Group 1) could diminish the CSR in that group.

Women in Group 5 (multiparous with prior CS, singleton, cephalic, term) had the second highest contribution to the CSR. Previous CS is still a common indication for CS ${ }^{[21]}$, more so in a facility where mothers can request for a repeat $\mathrm{CS}$ to avoid the pain of labour or possible adverse perinatal outcomes. Other multiparous mothers with previous CS would undergo a repeat CS because they did not meet the criteria for trial of vaginal birth after CS, have had at least two previous CS or failed a trial of vaginal birth after $\mathrm{CS}^{[22]}$. Improvement in fetal surveillance techniques could lead to a reduction in the number of primary CS done for fetal heart rate concerns. Efforts should also be made to restrict the diagnosis of failure to progress in labour to its true meaning, provided there is no direct harm to mother or baby. These will directly reduce the contribution of Group 1 to the overall CSR, and by extension, potentially reduce the contribution of Group 5 (multiparous women with previous CS) to the rising rates. Besides, dedicated vaginal birth after CS (VBAC) clinics could be established to counsel women using decision aids with a view to increasing the number of women accepting VBAC ${ }^{[23,24]}$. These VBAC units could also strategically design locally-useful eligibility criteria for trial of labour after CS, thereby improving the chances of success in women who wish to have VBAC.

Although the indications for the preterm births (Group 10) were not explored in this audit, a study from EKSUTH found a preterm birth rate of $5.7 \%{ }^{[25]}$, and concluded that addressing modifiable risk factors for preterm births will reduce this rate; this strategy could also contribute to a reduction in the need for CS for births before 37 weeks, and eventually reduce the input from Group 10 to the overall CSR.

Both Groups 6 (all nulliparous breech) and 7 (all multiparous breech) made up $4.7 \%$ of the overall CSR. External 
cephalic version has been shown to reduce CSR in women with breech-presenting foetuses ${ }^{[26]}$. Revisiting the skills for the procedure should be considered.

Although the Robson's classification does not include the rates of operative vaginal deliveries and the urgency of the caesarean sections, it has none-the-less provided a sound basis for comparison and standardizing of CSR within health facilities, and between facilities locally, nationally and internationally. Also, EKSUTH is a referral centre with a greater proportion of high risk cases. These findings may vary from those obtainable in lower-tier centres where CS is also performed.

\section{Conclusion}

This audit has shown that reducing CSR requires a multi-pronged approach: continuous training, coupled with drills on active management of labour, for relevant health care providers at all levels of health care on proficiency in labour management, including the use of the partograph. There is also need for development of locally-adapted eligibility criteria for selecting women for VBAC, coupled with strategies to allay the fear of pregnant women about VBAC. The skills/proficiency in instrumental vaginal delivery and procedure of external cephalic version should be revisited, as these skills are gradually being lost in contemporary obstetric practice. There should be improvement in our technology of diagnosing fetal distress, including the use of fetal blood sampling to confirm diagnosis.

\section{Conflict of interest}

The authors declared no conflict of interest.

\section{Author's contributions}

All the listed authors have critically worked on and assessed the quality of the manuscript. The study was conceptualized and written by BAO; JOA and AOA analyzed and review the manuscript; ODO and ASA helped in the review of the manuscript; ORO coordinated the data collection.

\section{Acknowledgement}

The authors appreciate the contributions of Mr Ibiyemi Sunday, our research assistant, and all the members of staff of Department of Obstetrics and Gynaecology, Ekiti State University Teaching Hospital, Ado - Ekiti.

\section{References}

[1] Dinas K, Mavromatidis G, Dovas D, Giannoulis C, Tantanasis T, Loufopoulos A, et al. Current caesarean delivery rates and indications in a major public hospital in northern Greece. Aust N Z J Obstet Gynaecol 2008;48:142-6.

[2] World Health Organization. Appropriate technology for birth. Lancet 1985;2:436-7.

[3] Gibbons L, Belizan JM, Lauer JA, Betran AP, Merialdi M, Althabe F. The Global Number and Costs of Additionally Needed and Unnecessary Caesarean Section Performed per Year: Overuse as a Barrier to Universal Coverage. World Health Report (2010) Background Paper, No 30; 2010
[4] Penna L. Management of the scarred uterus in subsequent pregnancies. Curr Obstet Gynaecol 2003;13:173-8.

[5] Yeoh SB, Leong SB, Heng AS. Anaesthesia for lowersegment caesarean section: Changing perspectives. Indian J Anaesth 2010;54:409-14.

[6] Giang HT, Ulrich S, Tran HT, Bechtold-Dalla Pozza S. Monitoring and interventions are needed to reduce the very high Caesarean section rates in Vietnam. Acta Paediatrica 2018 Dec;107(12):2109-14.

[7] Daniel CN, Singh S. Caesarean delivery: An experience from a tertiary institution in north western Nigeria. Niger. J. Clin. Pract 2016;19(1):18-24.

[8] Obiechina NJ, Ezeama CO, Ugboaja JO. A five-year review of Caesarean section in Nnamdi Azikiwe University Teaching Hospital, Nnewi Anambra State, Nigeria (1st Jan, 2002-31st Dec, 2006). Trop J Med Res 2008;12:29-32.

[9] Adekanle DA, Adeyemi AS, Fasanu AO. Caesarean section at a tertiary institution in South-Western Nigeria - A 6-year audit. Open J Obstet Gnaecol 2013;3:357-61.

[10] Tadevosyan M, Ghazaryan A, Harutyunyan A, Petrosyan V, Atherly A, Hekimian K. Factors contributing to rapidly increasing rates of cesarean section in Armenia: a partially mixed concurrent quantitative-qualitative equal status study. BMC pregnancy childb 2019;19(2). doi: 10.1186/s12884-018-2158-6

[11] Tanaka K, Mahomed K. The Ten-Group Robson Classification: A single centre approach identifying strategies to optimize caesarean section rates. Int J Gynecol Obstet 2017; Article ID: 5648938, 5 pages.

[12] FIGO Working Group on Challenges in Care of Mothers and Infants during Labour and Delivery. Best practise advice on the 10-Group Classification System for caesarean deliveries. Int $\mathbf{J}$ Gynecol Obstet 2016;135(2);232-3.

[13] UNESCO AP. Reaching the 2015 Literacy Target: Delivering on the promise. High Level International Round Table on Literacy, UNESCO, Paris. 2012 Sep:67.

[14] Adewuyi EO, Auta A, Khanal V, Bamidele OD, Akuoko CP, Adefemi K, Tapshak SJ, Zhao Y. Prevalence and factors associated with underutilization of antenatal care services in Nigeria: A comparative study of rural and urban residences based on the 2013 Nigeria demographic and health survey. PloS One 2018;13(5):e0197324.

[15] Lumbiganon P, Laopaiboon M, Gulmezoglu AM, Souza JP, Taneepanichskul S, Ruyan P, et al. Method of delivery and pregnancy outcomes in Asia: the WHO global survey on maternal and perinatal health 2007-08. Lancet 2010;375(9713):490-9

[16] MacDorman MF, Menacker F, Declercq E. Cesarean birth in the United States: epidemiology, trends, and outcomes. Clin Perinatol 2008;35(2):293-307.

[17] Barros FC, Vaughan JP, Victora CG, Huttly SR. Epidemic of caesarean sections in Brazil. Lancet 1991;338:167-9.

[18] Kazmi T, Saiseema S, Khan S. Analysis of Cesarean Section Rate - According to Robson's 10-group Classification. Oman Med J 2012;27(5):415-7.

[19] Kant A, Mendiratta S. Classification of cesarean section through Robson criteria: an emerging concept to audit the 
increasing cesarean section rate. Int J Reprod Contracept Obstet Gynecol 2018;7(11):4674-7.

[20] Walker R, Turnbull D, Wilkinson C. Strategies to address global caesarean section rates: A review of the evidence. Birth 2002;29(1):28-39.

[21] Villar J, Valladares E, Wojdyla D, Zavaleta N, Shah A, Campodónico $\mathrm{L}$, et al. Caesarean delivery rates and pregnancy outcomes: the 2005 WHO global survey on maternal and perinatal health in Latin America. Lancet 2006;367(9525):1819-29.

[22] Rossi CA, D'Addario V. Maternal Morbidity following a trial of labor after caesarean section vs elective repeat caesarean delivery: a systematic review with metaanalysis. Am J Obstet Gynecol 2008;199(3):224-31.
[23] Montgomery AA, Emmett CL, Fahey T, Jones C, Ricketts I, Patel RR, et al. Two decision aids for mode of delivery among women with previous caesarean section: randomised controlled trial. BMJ 2007;334(7607):1305.

[24] Gardner K, Henry A, Thou S, Davis G, Miller T. Improving VBAC rates: the combined impact of two management strategies. Aust N Z J Obstet Gynaecol 2014;54(4):327-332.

[25] Akintayo AA, Awoleke JO, Ogundare EO, Olatunya OS, Aduloju OP. Preterm births in a resource constrained settings: Sociobiologic risk factors and perinatal outcomes. Ghana Med J. 2015;49(4):251-7.

[26] Anderson GM, Lomas J. Determinants of the increasing caesarean birth rate - Ontario Data 1979 to 1982 . N Engl J Med 1984;311:887-92. 